\title{
Title
}

\section{Preparation of Hydrogen Permeable Membrane using Nanoparticles Electrophoresis Technique}

\section{Author}

Aki Tominaga, Yoshiteru Mizukoshi, Osamu Nakagoe, Shuji Tanabe*

\section{Author's affiliations}

A. Tominaga $\cdot$ S. Tanabe*

Graduate School of Science and Technology Nagasaki University, 1-14 Bunkyo-machi, Nagasaki, 852-8521, Japan

e-mail : s-tanabe@nagasaki-u.ac.jp

Y. Mizukoshi

Institute for Materials Research (IMF), Tohoku University, 1-2 Gakuen-cho, Naka-ku, Sakai, Osaka 599-8531, Japan

\section{O. Nakagoe}

Department of Materials Science and Engineering, Faculty of Engineering, Nagasaki University, 1-14 Bunkyo-machi, Nagasaki, 852-8521, Japan 


\begin{abstract}
Hydrogen perm-selective membranes composed of Pd nanoparticles were investigated. The nanoparticles were prepared by ultrasonic reduction from $\mathrm{Pd}^{\mathrm{II}}$ ions, and then deposited on a substrate disc with electrophoresis technique. These electrophoretic membranes have shown high performance of perm-selectivity for $\mathrm{H}_{2}$ with separation factor $\alpha=3.85$, under room temperature.
\end{abstract}

Keyword

Thin membrane $\cdot$ Hydrogen perm-selectivity $\cdot$ Electrophoresis $\cdot$ Nanoparticels 


\section{Introduction}

Stable supply of pure hydrogen is indispensable for practical uses of fuel cells, which are one of the most promising solutions to energy and environmental problems [1]. To produce large amounts of hydrogen, improving the performance of hydrogen perm-selective membrane is crucial and urgent. In general, thinner and denser membranes show high performance for hydrogen permeation due to decreasing time through the membrane and increasing collision frequency between gas and wall of micro pore in membrane, respectively. Pd and its alloy membranes are commercially used because they have higher permeability of hydrogen than that of the other gases $[2$, 3]. However, making thin membrane less than $2 \mu \mathrm{m}$ from $\mathrm{Pd}$ and its alloy by conventional methods is expensive and difficult [2-7].

On the other hand, many researchers have reported the preparation procedure of nanoparticles and nano composite particles in the last two decades. Those preparation procedures and the nature of nanoparticles were summarized in excellent reviews $[8,9]$. In many cases, a reducing agent such as $\mathrm{NaBH}_{4}, \mathrm{~N}_{2} \mathrm{H}_{2},\left(\mathrm{NH}_{2}\right)_{2} \mathrm{CO}$, or alcohol might be used on the preparation process. The nanoparticles, however, can be prepared without reducing agents. Kameo et al. reported that $\mathrm{Pd}$ and $\mathrm{Ag}$ nanoparticles could be prepared in supercritical fluid of carbon dioxide without any reducing agents [10]. Luo et al. also obtained mono-dispersed $\mathrm{Pd}$ nanoparticles with mixing $\mathrm{Pd}(\mathrm{OAc})_{2}$ and $\mathrm{PEG}$ at $80{ }^{\circ} \mathrm{C}$ [11]. One of the most unique preparation procedures in those reports may be the sonochemical process. Okitsu et al. [12] have reported the sonochemical reduction process of noble metal ions, and obtained well dispersed Pd nanoparticles. The sonochemical technique has some advantages such as controllable particle size, short preparation time, no further thermal treatment required, etc. In sonochemical process, 
active species such as hydroxy radicals, hydrogen radicals, and hydrocarbon radicals form due to cavitation phenomena if water contains organic compounds. Okitsu et al. claimed that the hydrocarbon radicals acted as reducing agents in the sonochemical process. They also suggested that the population (concentration) of the cavities was very small and the lifetime was very short. This was the reason well dispersed nanoparticles could be prepared with sonochemical process. Therefore, we expected that ultra thin membranes could be fabricated for gas separation if the monodispersed nanoparticles could be prepared and stacked uniformly on the porous substrate. The conventional methods for making gas perm-selective membrane, such as electrodeposition, chemical vapor deposition (CVD), and spin coating etc., are difficult to make uniformed micro pores. Hence, we focus the electrophoretic deposition of nanoparticles on porous substrate. This method can be utilized for making well ordered $2 \mathrm{D}$ or $3 \mathrm{D}$ arrays of nanoparticles without any collapse or coagulation $[13,14]$. The interspace between arrayed nanoparticles can be utilized as uniformed micro pore for gas-streaming path. The objective of this work is to establish a novel preparation process of hydrogen perm-selective thin membranes by electrophoresisically bottom-up of noble metal nanoparticles. 


\section{Experimental}

\subsection{Preparation of Nanoparticles}

Monodispersed $\mathrm{Pd}$ nanoparticles were prepared from $\mathrm{Pd}^{\mathrm{II}}$ aqueous solution with sonochemical reduction procedure which was described elsewhere [12, 15-17]. Designated amounts of $\mathrm{PdCl}_{2} \cdot 2 \mathrm{NaCl} \cdot 3 \mathrm{H}_{2} \mathrm{O}$ (Wako Pure Chemical Industries, Ltd., Japan) and poly-ethylene(40)glycol monostearate (PEG40-MS, Tokyo Chemical Industry Co., Ltd.) were added into ultra pure water $(0.1-0.4 \mathrm{mM})$. The solutions were stirred for several hours. $100 \mathrm{~mL}$ of the solution was put in the irradiation glass vessel, and was purged with pure Ar for 20 min. Ultrasonic irradiation was carried out at room temperature, using a multi-wave ultrasonic generator (Kaijo Co., Ltd, TA-4021, Condition: $200 \mathrm{kHz}, 6.0 \mathrm{~W} / \mathrm{cm}^{2}$ ) equipped with a barium titanate oscillator of $65 \mathrm{~mm}$ in diameter. UV-vis spectra of the solutions before and after ultrasonic irradiation were measured to check the nanoparticles formation. The obtained Pd nanoparticles were observed with high resolution transmission electron microscope (HR-TEM) (JOEL, JEM-200-HR).

\subsection{Assembly of nanoparticles membrane}

Hydrogen perm-selective membranes were prepared by electrophoresis technique with U-shaped glass tube equipped with Pt electrodes. Pd nano colloidal solution was put in the cathodal side in the electrophoretic bath because the Pd nanoparticles moved to anodic side due to negative zeta potential when the DC electric potential was applied to the solution. Constant-voltage power supply (ATTO CORPORATION, AE-8350) was used on electrophoresis (Electrophoresis condition: DC $500 \mathrm{~V}, 37-65 \mathrm{~mA}, 3 \mathrm{~min}$ ). A commercially supplied porous alumina disc (AAO disc) (Anodisc13, Whatman 
International Ltd.) was used as substrate to support Pd membrane. The AAO disc has $0.02 \mu \mathrm{m}$ in pore size, $13 \mathrm{~mm}$-diameter, $60 \mu \mathrm{m}$ in thickness.

The morphologies and composition of the assembled membrane were observed by field-emission scanning electron microscopy (FE-SEM, JEOL Ltd. JSM-7500FA) and dispersive x-ray (EDS) analysis.

\subsection{Evaluation of membrane}

Gas permeance of the membrane was measured in a batch mode using the membrane test system depicted in Fig. 1. A piece of membrane was fixed in a glass sample holder, which was connected to a vacuum line equipped with pressure Transducer (Baratron ${ }^{\circledR}$ 222BA, MKS Instr. Ink.), diffusion, and rotary vacuum pump. Using the purity of hydrogen was $99.999 \%$. A constant amount of hydrogen or nitrogen was introduced into up-stream side of membrane. Permeations of air and $\mathrm{H}_{2}$ were evaluated from the pressure changes on both sides of membrane while the gas was being introduced into one side of the membrane under room temperature.

$q\left(\right.$ Volume of permeation $\left.\left[\mathrm{cm}^{3}\right]\right), R$ (permeability coefficient $\left.\left[\mathrm{mol}\left(\mathrm{m}^{2} \cdot \mathrm{sec} \cdot \mathrm{Pa}\right)^{-1}\right]\right)$, and $\alpha$ (separation factor) were given by,

$$
\begin{aligned}
& q=P\left(p_{1}-p_{2}\right) A \Delta t / l \quad \cdots(1), \\
& R=P / l \quad \cdots(2), \\
& \alpha_{\left(\mathbf{H}_{2} / \mathbf{N}_{2}\right)}=R_{\mathbf{H}_{2}} / R_{\mathbf{N}_{2}} \quad \cdots(3),
\end{aligned}
$$

where $P$ is transmission coefficient $\left[\mathrm{mol} \cdot \mathrm{m}\left(\mathrm{m}^{2} \cdot \mathrm{sec} \cdot \mathrm{Pa}\right)^{-1}\right],\left(p_{1}-p_{2}\right)$ is differential pressure $[\mathrm{Pa}], A$ is membrane area $\left[\mathrm{m}^{2}\right], t$ is differential time $[\mathrm{sec}], l[\mathrm{~m}]$ is membrane thickness. Therefore, $P$ and $R$ value s were introduced from measurement of the 
differential pressure, $\left(p_{1}-p_{2}\right)$, and equation (1) to (3). 


\section{Results and Discussion}

Obtained Pd nanoparticles from sonochemical reduction were confirmed by UV-vis spectra and TEM observations. The absorption peak about $400 \mathrm{~nm}$ due to $\mathrm{Pd}^{\mathrm{II}}$ complex decreased as the irradiation time was increased, while broad absorption band corresponded to $\mathrm{Pd}^{0}$ nanoparticles was increasing. The color of the solution also changed from yellow to dark gray after $20 \mathrm{~min}$ of the irradiation. Therefore, it was ascertained that the reduction of $\mathrm{Pd}^{\mathrm{II}}$ had finished at $20 \mathrm{~min}$ of irradiation because the $400 \mathrm{~nm}$ of absorption peak completely disappeared and no more change of the broad absorption band occurred after further irradiation.

A TEM image and particle size distribution are shown in Fig. 2 (a) and (b), respectively. The average particle size was calculated as $4.01 \mathrm{~nm}$, and very narrow size distribution was also obtained. From this observation, it was clear that the monodispersed ultra fine Pd nanoparticles were successfully obtained by ultrasonic technique. The obtained Pd colloidal solution was very stable because there was no agglomeration for two months and more stock at room temperature.

An electrophoresis method was applied to prepare thin layer membrane which consisted of Pd nanoparticles. Prior to the electrophoresis process, the zeta potential of $\mathrm{Pd}$ nano colloid was measured with $-11.0 \mathrm{mV}$ at 2.9 of $\mathrm{pH}$ at room temperature, and decreased monotonically with increasing $\mathrm{pH}$ above 2.5 . Since the $\mathrm{pH}$ value of the solution changed from 2.9 to 3.4 after electrophoresis, Pd nanoparticles always migrated to anodic side during this process. Before electrophoresis process, many micro pores on the surface of AAO disc were observed by FE-SEM observation as shown in Fig. 3 (a). Those micro pores completely disappeared after the process (Fig. 3 (b)), and the white color of original AAO disc changed to black, which meant the Pd nano particles were 
moved and stacked on the surface of the disc. The cross-sections of the obtained membranes were observed with FE-SEM. Before the electrophoresis, there were many pores observed as vertical lines which were perpendicular to the surface (horizontal bright line on the Fig. 4 (a)). A reflection image of field emission SEM after the electrophoresis is shown in Fig. 4 (b). The many micro pores near the surface could not be observed. Also, the image of the substrate near the surface was brighter than that of inside of the substrate (top part on the picture). From the results, it was suggested that the Pd nanoparticles could be deposited on the surface of the substrate by the electrophoretic process. To confirm the consideration an energy dispersive analysis of X-ray emission was carried out in the SEM observation, and the obtained image of Pd component is shown in Fig. 4 (c). It was clearly confirmed that the Pd nanoparticles were located near the surface because the bright points from Pd particles appeared bottom area on the picture.

The gas permeance properties of obtained Pd membranes are summarized in Table 1. The permeances of hydrogen and nitrogen decreased with increasing the initial $\mathrm{Pd}^{\mathrm{II}}$ concentrations. On the other hand, the separation factor increased with increasing the concentrations. The reason why the properties depended on the Pd concentration was the difference of nanoparticles concentrations in colloidal solution. Therefore, it's thought that the nanoparticles in a concentrated solution are stacked tightly on the substrate surface and became thick membrane. Hurlbert et al. [18] reported that diffusion of hydrogen was rate determining step for thick Pd membrane ( $>20 \mu \mathrm{m})$. They claimed that the hydrogen flux was proportional to the square root of hydrogen pressure, when the hydrogen permeation occurs due to dissolution of $\mathrm{H}$ atoms into bulk Pd via dissociation of $\mathrm{H}_{2}$ on surface of membrane. To determine the permeation mechanism 
gas flux is plotted as function of difference of partial pressure in permeation experiments as shown in Fig. 5. The gas flux is approximately proportional to the difference of partial pressure, not in the square root of it. This indicates that rate-limiting in hydrogen transport is not caused from dissolution into bulk Pd but migration through meso or micropore in membrane [2]. In general, four types of diffusion mechanisms can be utilized to effective gas separation in porous membrane. These are Knudsen diffusion, surface diffusion, capillary condensation, and molecular sieving. Nam et al. reported surface diffusion membrane prepared by vacuum electrodeposition of $\mathrm{Pd}$ on porous substrate [2]. They obtained high gas separation factor of above 4700 for $\mathrm{H}_{2} / \mathrm{N}_{2}$ at $823 \mathrm{~K}$. In addition, Mercea et al. also reported $\mathrm{H}_{2} / \mathrm{N}_{2}$ separation factor of 33 for $\mathrm{Pd}$ deposited polymer membrane even at room temperature, although $\mathrm{H}_{2}$ dissociation on Pd surface is activated process [19]. In the case of this work, however, we got separation factor of 3.85 even at the best preparation condition. Therefore, the membranes in this work seem not to permeate $\mathrm{H}_{2}$ via surface diffusion.

The pore diameter of the membrane strongly influences the permeation mechanism to vary gas separation factor and permeance [20]. To discuss the permeation mechanism in this work furthermore, the diameter of micro pore between Pd nanoparticles was calculated. It was obvious that the membrane consisted of spherical particles of $4 \mathrm{~nm}$ in diameter from TEM observations. The micro pores of the membrane were $0.6 \mathrm{~nm}$ assuming that the membrane consists of well-ordered array of spherical nanoparticles, which have equivalent diameter and shape. The porous membrane can act as molecular sieving one for $\mathrm{H}_{2}$ separation, when the pore size is between $0.289 \mathrm{~nm}$ of kinetic diameter of $\mathrm{H}_{2}$ and $0.346 \mathrm{~nm}$ of that of $\mathrm{N}_{2}$ [21]. The pore size of our membrane has about two times larger for that of molecular sieving membrane. Moreover, the 
separation factor tends to become higher than that of Knudsen diffusion [22-24]. Therefore molecular sieving mechanism can be ruled out because the path diameter is larger than the molecular size, $0.6 \mathrm{~nm}$, but smaller than the mean free-path, $70 \mathrm{~nm}$ in our membrane. In the case of capillary transport, separation factor $\alpha$ and permeance strongly depends on pore size, its distribution, and working condition, such as pressure and temperature [20]. Especially, the differences of separation factor from Knudsen value have been observed from capillary-transported membrane with pore size of several times larger than kinetic diameter up to $2 \mathrm{~nm}[25,26]$. Hassan et al. reported $\mathrm{O}_{2} / \mathrm{N}_{2}$ separation factor of 8.5 around room temperature using silica based membrane [27]. However, Brinker et al. reported that $\mathrm{He} / \mathrm{N}_{2}$ ideal separation factors of membrane with pore size below $1 \mathrm{~nm}$ were less than the calculated Knudsen value [28]. Most of capillary transport membranes with pore size below $2 \mathrm{~nm}$ show higher separation factor than Knudsen value around room temperature with except to $\mathrm{He} / \mathrm{N}_{2}$ separation. Additionally, the diffusivity of gas decreases very rapidly with reduction of pore size, particularly below $1 \mathrm{~nm}$ [26], because occupation of gas molecule in micro pore occurs more easily with decreasing pore diameter. In our case, the membrane prepared from 1 $\mathrm{mM}$ of initial Pd concentration had permeance of two orders of magnitude smaller than $0.4 \mathrm{mM}$. This implies that the average pore size of the resulting membranes was close to several $\mathrm{nm}$ and gas molecules were easy to occupy micro pore. However the permeance of our membranes was two or three orders of magnitude higher than typical one of capillary transport. Based on these findings, it is concluded that the gas permeation in this membrane follows the Knudsen diffusion [1, 3], although we could not rule out capillary transport mechanism completely.

Although interspaces between Pd nanoparticles could not be controlled as micro 
pore of ideal molecular sieving membrane ranging from 0.289 to $0.364 \mathrm{~nm}$, we demonstrated hydrogen perm-selective micro porous membrane by use of this novel procedure. Precise size control of micro pore should be required for appropriate condition, such as applied voltage, deposition time, particle size, and choice of surfactant etc. Further experiments are planed to elucidate the appropriate condition and gas diffusion mechanism for this perm-selective membrane. In addition, the procedure dose not depend on composition of nano materials, including in semiconductor, isolator, and polymer particle, because they have essential zeta potential at their surface. Therefore some of problem, however, should be solved, we suggested that the novel permeation procedure become promising one. 


\section{Conclusions}

In summary, we developed new preparation procedure which could make the very thin hydrogen perm-selective membrane. The procedure consisted of two preparation steps, one was the preparation of nanoparticles by ultrasonic irradiation, and the other was deposition of the particles on a substrate by the electrophoresis method. The hydrogen permeance rate and hydrogen-nitrogen separation factor of the obtained membrane showed very high performance at the room temperature. Detailed diffusion mechanism analysis and optimization of electrophoretic condition are underway. However, it is expected that this new method has some potentials to spread widely and to make many kind of ultra thin perm-selective membrane easily. 


\section{Acknowledgement}

This study was financially supported by Mukai Science and Technology Foundation. 


\section{Reference}

[1] G.Q. Lu, J.C. Diniz da Costa, M. Dukec, S. Giessler, R. Socolow, R.H. Williams, T. Kreutze, J. Colloid Interface Sci. (2007) 314589.

[2] S.-E. Nam, S.-H. Lee, K.-H. Lee, J. Membr. Sci. 153 (1999) 163.

[3] A.L. Mejdell, H. Klette, A. Ramachandran, A. Borg, R. Bredesen, J. Membr. Sci. 307 (2008) 96.

[4] J. Shu, B.P.A. Grandjean, E. Ghali, S. Kaliaguine, J. Membr. Sci. 77 (1993) 181.

[5] S. Yan, H. Maeda, K. Kusakabe, S. Morooka, Ind. Eng. Chem. Res. 33 (1994) 616.

[6] G. Xomeritakis, Y.S. Lin, J. Membr. Sci. 133 (1997) 217.

[7] S. Yamaura, S. Nakata, H. Kimura, A, Inoue, J. Membr. Sci. 291 (2007) 126.

[8] J. Park, J. Joo, S.G. Kwon, Y. Jang, T. Hyeon, Angew. Chem. Int. Ed. 46 (2007) 4630.

[9] N. Toshima, T. Yonezawa, New J. Chem. (1998) 1179.

[10] A. Kameo, T. Yoshimura, K. Esumi, Colloids and Surfaces A Physicochem. Eng. Aspects 215

(2003) 181-189

[11] C. Luo, Y. Zhang, Y. Wang, J. Molecular Catalysis A Chem. 229 (2005) 7.

[12] K. Okitsu, A. Yue, S. Tanabe, H. Matsumoto, Chem. Mater. 12 (2000) 3006.

[13] A. R. Boccaccini, J. A. Roether, B. Thomas, M. S. P. Shaffer, E. Chavez, E. Stoll, J Ceram Soc Jpn. 114 (2006) 1.

[14] T. Yonezawa, S. Onoue, T. Kunitake, Adv. Mater. 10 (1998) 414.

[15] A. Nemamcha, J.-L. Rehspringer, D. Khatmi, J. Phys. Chem. B 110 (2006) 383.

[16] Y. Mizukoshi, T. Fujimoto, Y. Nagata, R. Oshima, Y. Maeda, J. Phys. Chem. B. 104 (2000) 6028.

[17] Y. Mizukoshi, Y. Tsuru, A. Tominaga, S. Seino, N. Masahashi, S. Tanabe, T. A. Yamamoto, Ultrasonics Sonochem. 15 (2008) 875.

[18] R.C. Hurlbert, J.O. Konecny, J. Chem. Phys. 34 (1961) 655.

[19] P.V. Mercea, D. Silipas, V. Mecea, Gas. Sep. Purif. 4 (1990) 137.

[20] R.D. Noble, S.A. Stern, Membrane Separations Technology - Principles and Applications, Elsevier Science B. V., 1995, Amsterdam.

[21] D.W. Breck, Zeolote Molecular Sieves; Structure, Chemistry and Use, John Wiley and Sons, New York, 1973, p636.

[22] J.J. Hammel, U.S. Patent 4,853,001, August 1, 1989.

[23] J.J. Hammel, W.J. Robertston, W.P. Marshall, H.W. Barch, B. Das, M.A. Smoot, R.P. Beaver, U.S. Patent 4,842,2620, June 27, 1989.

[24] J.D. Way, D.L. Roberts, Sep. Sci. Technol. 27 (1992) 29.

[25] R.S.A. de Lang, K. Keizer, A.J. Burggraaf, J. Memb. Sci. 104 (1995) 81.

[26] M.B. Rao, S. Sircar, J. Memb. Sci. 110 (1996) 109.

[27] M.H. Hassan, J.D. Way, P. M. Thoen, A. C. Dilon, J. Memb. Sci. 104 (1995) 27.

[28] C.J. Brinker, T.L. Ward, R. Sehgal, N.K. Raman, S.L. Hietala, D.M. Smith, D.-W. Hua, T.J. Headley, J. Memb. Sci. 77 (1993) 165. 


\section{Table}

Table 1 Gas permeation properties of prepared membranes.

\begin{tabular}{|c|c|c|c|c|}
\hline \multicolumn{2}{|c|}{ Membrane } & \multicolumn{2}{|c|}{$\begin{array}{c}\text { Permeance R } \\
{\left[\mathrm{mol} \cdot \mathrm{m}^{-2} \cdot \mathrm{sec}^{-1} \cdot \mathrm{Pa}^{-1}\right]}\end{array}$} & \multirow{2}{*}{ Separation factor $\alpha^{*}$} \\
\hline Material & Pd conc. (mM) & $\mathrm{H} 2$ & $\mathrm{~N} 2$ & \\
\hline AAO & - & $1.53 \times 10^{-4}$ & $6.09 \times 10^{-5}$ & 2.51 \\
\hline $\mathrm{Pd} / \mathrm{AAO}$ & 0.1 & $2.04 \times 10^{-4}$ & $6.35 \times 10^{-5}$ & 3.21 \\
\hline $\mathrm{Pd} / \mathrm{AAO}$ & 0.4 & $7.03 \times 10^{-6}$ & $1.83 \times 10^{-6}$ & 3.85 \\
\hline
\end{tabular}




\section{Figure}

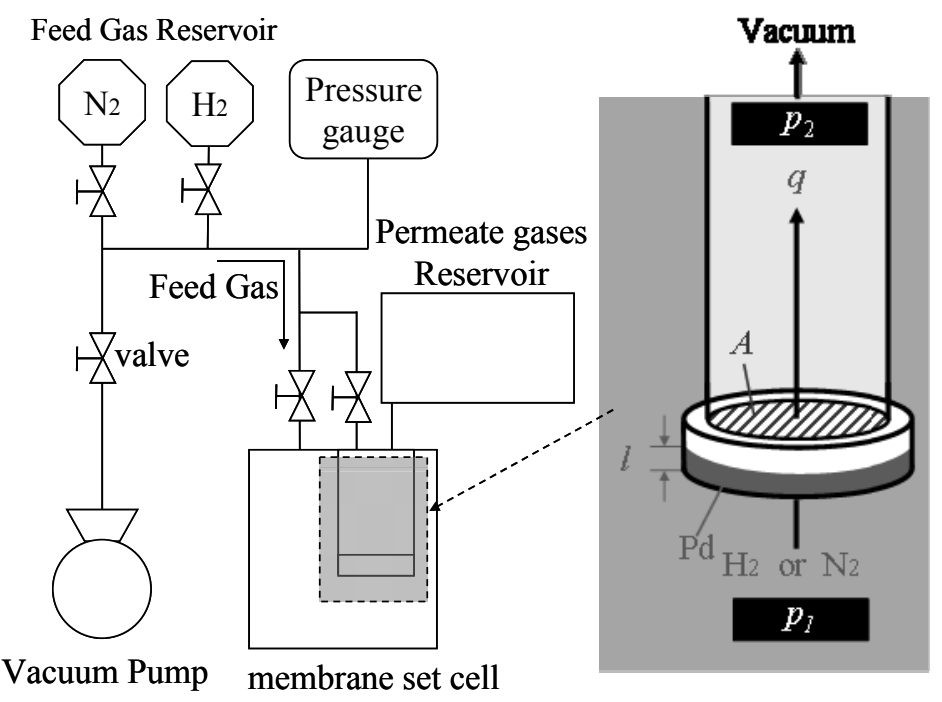

Fig. 1. Measurement set up of membrane perm-selectivity
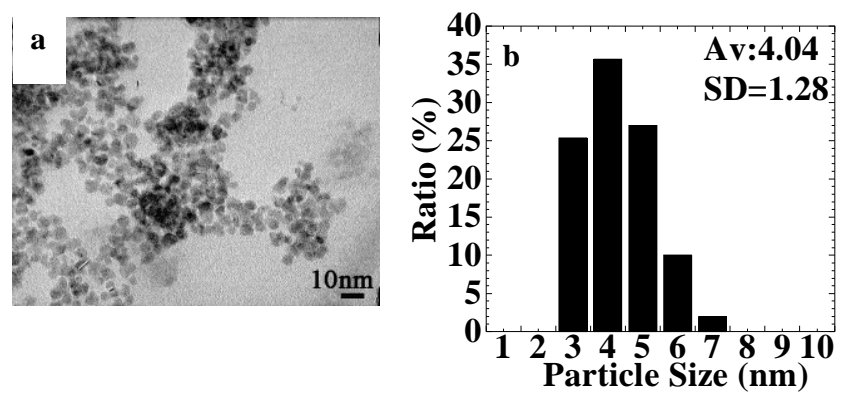

Fig. 2. HR-TEM photograph (a) and size distribution of Pd nanoparticles (b), sonochemically preparated ultrasonic irradiation was carried out using a multi-wave ultrasonic generator $\left(200 \mathrm{kHz}, 6.0 \mathrm{~W} / \mathrm{cm}^{2}\right)$, a barium titanate oscillator of $65 \mathrm{~mm}$ under Ar atmosphere. 


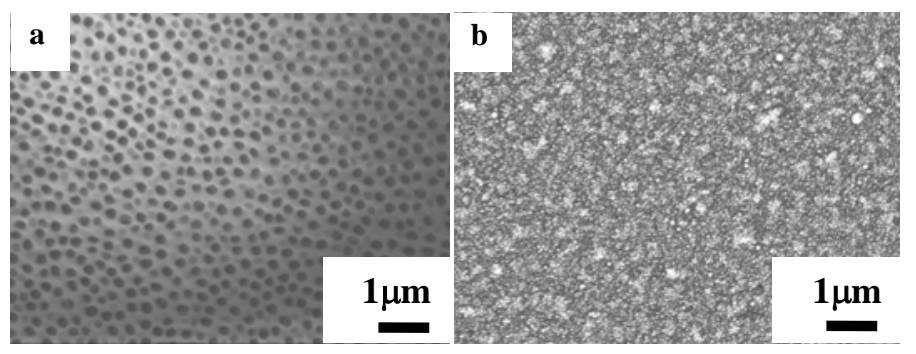

Fig. 3. FE-SEM Photographs of surface of membranes before (a) and after (b) electrophoresis. (Initial Pd concentration: $0.4 \mathrm{mM}$, Electrophoresis condition: $500 \mathrm{~V}, 3 \mathrm{~min}$ )
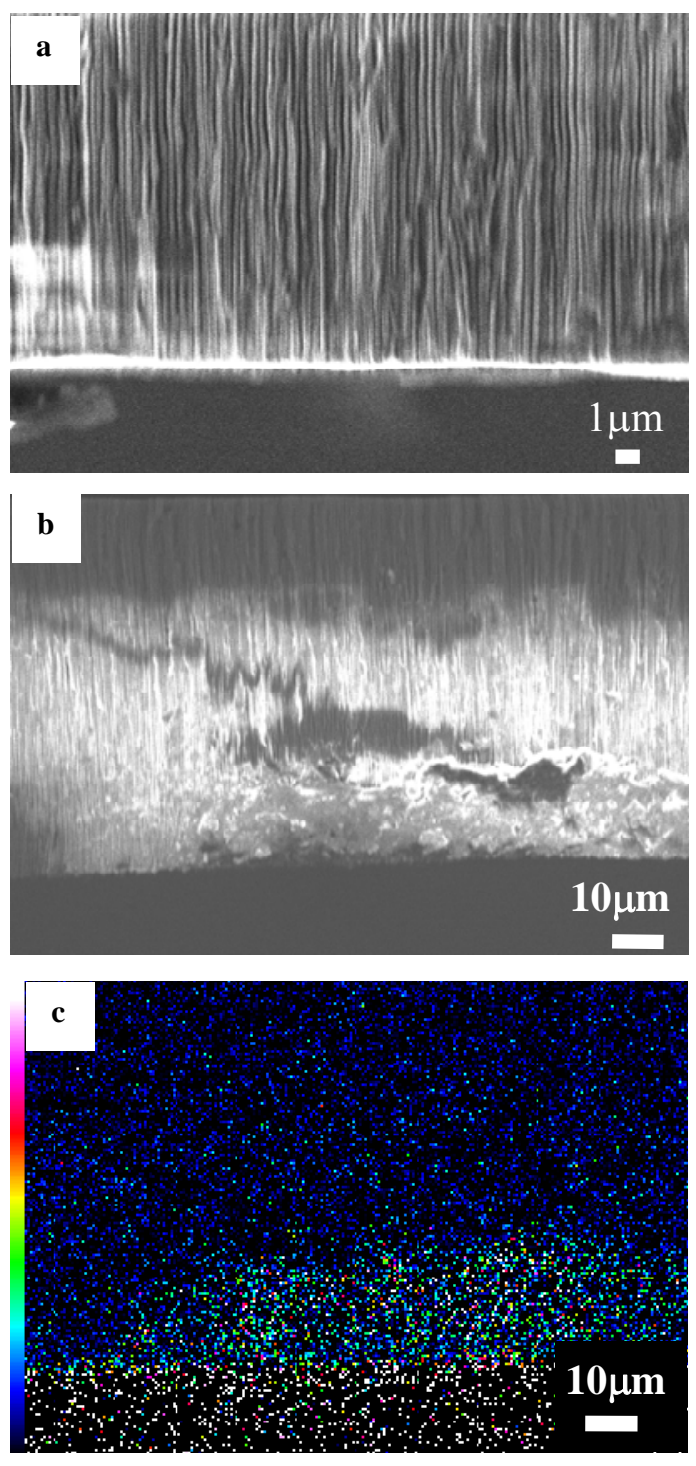

Fig. 4. FE-SEM Photographs of crosssection of membranes before (a) and after (b) electrophoresis. And (c) is the result of EDS analysis shows signal of Pd element. (Initial Pd concentration: $0.4 \mathrm{mM}$ ) 


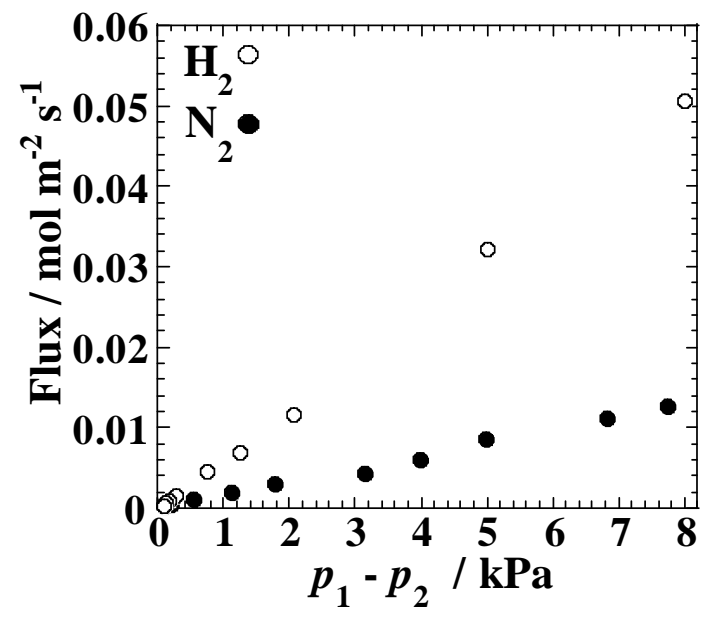

Fig. 5. Hydrogen $(\circ)$ and nitrogen $(\bullet)$ flux through the membranes as a function of the difference of the each gas partial pressures. Permeations results of membrane which were prepared using $0.4 \mathrm{mM}$ Pd colloidal solution. 